\title{
Avaliando os atributos da área afetiva na EAD
}

Ivan Soares dos Santos, Departamento de Ensino e Cultura do Exército - Exército

Brasileiro - Ministério da Defesa (DECEx/MD), soares@ decex.ensino.eb.br

Adriana Dallacosta, Departamento de Ensino e Cultura do Exército - Exército Brasileiro - Ministério da Defesa (DECEx/MD), adrianadalla@uol.com.br

Giselle Cazetta, Núcleo de Estudos Assistidos por Mídias Interativas - Universidade Federal Fluminense (NEAMI/UFF), Departamento de Ensino e Cultura do Exército Exército Brasileiro - Ministério da Defesa (DECEx/MD), giselle@ neami.uff.br

Sergio Guedes de Souza, Núcleo de Computação Eletrônica - Universidade Federal do Rio de Janeiro (NCE/UFRJ), guedes@nce.ufrj.br

Evaluating affective attributes in online courses

\begin{abstract}
The Brazilian Army uses the affective attributes in the training courses provided to officers, noncommissioned officers and soldiers to evaluate the behaviors and attitudes required to perform a military task. However for the online courses (e-learning) this evaluation type does not exist. This paper aims to present the design of a methodology to evaluate the affective attributes for the Brazilian Army online courses, and discuss its implementation in a pilot course to training military online instructors.
\end{abstract}

Resumo. O Exército Brasileiro utiliza nos seus cursos presenciais para formação de oficiais, subtenentes e sargentos os atributos de afetividade para avaliar os comportamentos e atitudes necessárias ao desempenho da tarefa. No entanto, para os cursos na modalidade de Educação a Distância essa avaliação não existe. Este artigo visa apresentar a concepção de uma metodologia para avaliação da área afetiva em cursos online para o Exército Brasileiro, e discute a sua aplicação em um curso piloto para formação de instrutores online nas escolas militares.

\section{Introdução}

O Exército Brasileiro (EB) utiliza no processo de avaliação de seus oficiais, subtenentes e sargentos três domínios avaliativos: o cognitivo, o psicomotor e o afetivo. A avaliação afetiva é considerada pelo EB um requisito fundamental para o exercício das funções inerentes ao militar: como pode um especialista em desarme de artefatos explosivos não possuir o atributo afetivo meticulosidade? Pode um piloto de helicóptero 
não possuir o atribuito afetivo equilíbrio emocional? Essas questões são estratégicas na formação de qualidade dos quadros da organização.

Apesar dessa diretriz estar bem estabelecida nos cursos na modalidade presencial, na modalidade de Ensino a Distância (EAD) ela não era utilizada em virtude da inexistência de uma metodologia que atendesse às necessidades. No entanto, no início de 2010, o Departamento de Educação e Cultura do Exército (DECEx) decidiu iniciar um experiemento piloto, desenvolvendo um curso de formação de professores online - o Estágio Setorial de Instrutores Online (ESIO) - utilizando uma metodologia de avaliação afetiva para EAD desenvolvida pela equipe da seção de educação a distância do DECEx.

Com a aplicação do curso, entendia-se ser possível validar a metodologia proposta avaliando corretamente os alunos no que tange ao domínio afetivo. Além disso, se a avaliação fosse bem sucedida, haveria uma melhora na formação dos professores online e, por consequência, dos cursos via EAD ministrados aos quadros da organização.

Este artigo tem como finalidade apresentar a metodologia de avaliação do domínio afetivo em cursos online e apresentar os dados relativos à aplicação desta em um curso de formação de professores online.

Este artigo está organizado da seguinte forma: a seção 2 apresenta o referencial teórico que fundamenta o uso do domínio afetivo no Exército Brasileiro, a seção 3 apresenta a metodologia de avaliação do domínio afetivo proposta nesse artigo, a seção 4 mostra a aplicação da metodologia e a seção 5 apresenta as considerações finais.

\section{Domíno Afetivo no Exército Brasileiro}

A aprendizagem transcende os limites de aquisição de conhecimentos (área cognitiva). Bloom (1983) dividiu a aprendizagem em três grandes domínios: o domínio cognitivo, que abrange os aspectos intelectuais; o psicomotor, que abrange as habilidades de execução de tarefas afetas ao organismo muscular; e o domínio afetivo, que abrange os aspectos de sensibilização, atitudes e gradação de valores.

Longhi et al (2009, p. 204) atribuem papel de destaque ao domínio afetivo ao afirmarem que "É mediante a avaliação da aprendizagem que se obtêm as informações relevantes sobre o aluno, como ele se desenvolve e constrói o conhecimento. Entretanto, a avaliação do processo de aprendizagem deve ir além da verificação do alcance dos objetivos em relação ao conteúdo, procurando levar em consideração o afeto e os atributos afetivos subjacentes do aluno, uma vez que interferem profundamente nos processos mentais, como memorização, raciocínio, atenção, motivação, etc."

Ao tratar avaliação da aprendizagem na educação online, é significativo entender as relações em um Ambiente Virtual de Aprendizagem (AVA). Alguns comportamentos e atitudes inerentes aos discentes nos AVAs como ausência; silêncio virtual; presença; participação; dentre outros devem ser observados e acompanhados com atenção por parte do professor online (OKADA e DE ALMEIDA, 2006).

Nos AVAs, as trocas textuais entre professores-discentes e discentes-discentes são comuns e, via de regra, a escrita assume uma estrutura sintático-semântica similar a 
oralidade. Porém, a escrita digital, em virtude da possibilidade de registro e acompanhamento do processo ensino aprendizagem, presta-se mais à análise das interações dos educadores e intervenção sobre as mesmas, do que se ocorressem oralmente (PESCE e BRAKLING, 2006).

$\mathrm{Na}$ avaliação de aspectos do domínio afetivo, fazer com que o discente expresse comportamentos dentro de um contexto interativo. Silva (2006) nos apresenta uma reflexão sobre a interatividade como sustentáculo da aprendizagem valorizando a autonomia, dialógica, participação e colaboração. E nesse contexto, Silva (2006, p.24) afirma que "O velho modelo de avaliação perderá a centralidade no novo contexto sócio-técnico. Isso abrirá espaço para a construção de novas práticas de aprendizagem $e$ de avaliação em sintonia com a dinâmica de nosso tempo. (...)”, o que nos conduz a redefinir a avaliação, em especial a avaliação interativa.

Ao se pensar no desenvolvimento tecnológico dos ambientes virtuais de aprendizagem, é razoável depreender que algumas implicações estarão voltadas para aspectos pedagógicos dos cursos online tais como: currículo; projeto pedagógico; e avaliação da aprendizagem (NUNES e VILARINHO, 2006).

\subsection{Domíno Afetivo no Exército Brasileiro}

No Exército Brasileiro este processo tem como ponto de partida o Projeto de Desenvolvimento e Avaliação dos Atributos da Área Afetiva, elaborado em 1997, para capacitar os recursos humanos da Força Terrestre.

De fato, a origem histórica deste projeto tem início na década de 1970, quando em 1972, realizaram-se os estudos que se concretizaram na edição, em 1975, do novo Manual do Instrutor: o T21-250 (FERNANDES, 2008).

O movimento que começou com estes estudos iniciais aprofundou-se e permitiu que se estabelecessem novas bases para o ensino e a instrução militar no Brasil, cujo marco relevante foi o projeto Objetivos Afetivos, desenvolvido de 1973 a 1980. Neste projeto, o grupo de pesquisa utilizou as teorias de Bloom inovando a área de ensino e recursos humanos do Exército (FERNANDES, 2008).

Em 1995, foi criado o Grupo de Trabalho para Estudo da Modernização do Ensino (GTEME) que estabeleceu, em 1997, o Projeto de Desenvolvimento e Avaliação dos Atributos da área Afetiva, com a finalidade de:

- implantar uma sistemática de operacionalização dos atributos da área afetiva nos planos de disciplinas;

- construir um instrumento para avaliar verticalmente os atributos constantes dos objetivos de ensino da área afetiva, nos Estabelecimento de Ensino do Departamento, exceto Colégio Militar e Escola Preparatória de Cadetes;

- e orientar o corpo docente dos Estabelecimentos de Ensino nos trabalhos de desenvolvimento e avaliação dos atributos (FERNANDES, 2008).

Com estes estudos, o Exército Brasileiro teve como objetivo implantar, nos cursos presenciais, esta nova metodologia para capacitar recursos humanos para a ocupação de cargos e o desempenho de funções. 
Para sistematizar o Projeto de Desenvolvimento e Avaliação dos Atributos da Área Afetiva o Exército elaborou duas portarias que são a base da metodologia: Brasil (1998) e Brasil (2000) que tratam respectivamente da elaboração dos conceitos utilizando os atributos da área afetiva e a que orienta os docentes nos procedimentos de desenvolvimento e avaliação dos atributos (FERNANDES, 2008 ).

\section{A metodologia}

O desenvolvimento da metodologia tomou como base o estabelecimento de uma estratégia que permitisse a observação e aquisição de dados sobre os comportamentos exteriorizados pelos discentes. Os passos a cumprir para a construção dessa metodologia estabeleceu-se por meio das seguintes etapas:

\subsection{Perfil profissiográfico}

Em primeiro lugar deve-se estabelecer um perfil profissiográfico do concludente do curso - entende-se por perfil profissiográfico como um retrato do profissional que o curso habilitou e capacitou para o desempenho de suas funções e atividades dentro dos objetivos e interesses da instituição e apresentar os principais atributos/comportamentos a serem trabalhados durante o curso (BRASIL, 2000).

\subsection{Objetivos afetivos}

A coordenação pedagógica do curso, juntamente com os professores, deve propor objetivos afetivos a serem alcançados pelos discentes em cada disciplina ou módulo do curso. Para cada assunto/conteúdo poderá ser elaborado 1 (um) objetivo afetivo.

É importante que o objetivo afetivo definido expresse a atitude que o discente deve adotar durante uma determinada atividade do curso, tal como interagir com os professores e colegas de curso, tratando-os com cordialidade e atenção (BRASIL, 2000).

Este objetivo afetivo, se alcançado pelo discente, conduz ao atributo sociabilidade.

\subsection{Pautas comportamentais}

É necessário a construção de pautas comportamentais para cada atributo a ser trabalhado e avaliado. A pauta serve como rubrica para avaliação comportamental a ser realizada pelo professor e não deve ser de conhecimento do discente.

É recomendado estabelecer de 3 (três) a 5 (cinco) pautas para cada atributo. Por exemplo, para o atributo sociabilidade poderiamos ter:

a) durante as atividades do fórum de discussão o aluno interagiu com seus professores e colegas de curso?

b) durante as atividades do fórum de discussão o aluno não interagiu com seus professores e colegas de curso?

c) durante as atividades do fórum de discussão o aluno interagiu com seus professores e não interagiu com os colegas de curso?

3.4 Atividades pedagógicas

V. $8 \mathrm{~N}^{\mathrm{o}} 3$, dezembro, 2010 
Este é o ponto crítico da metodologia, pois para permitir que o professor observe os atributos afetivos é preciso fazer com que eles sejam exteriorizados pelo discente e, mais complexo no meio online, captados sem nenhuma perturbação.

Em um AVA os professores têm acesso a ferramentas e facilidades que possibilitam criar e conduzir atividades pedagógicas que exigem ações do aluno para responder; debater; colaborar; e criar. No entanto, a seleção das atividades pedagógicas que permitam a observação de determinado comportamento necessita um esforço de adequação das interfaces do AVA aos atributos afetivos a serem trabalhados. Por exemplo, para trabalhar o atributo tolerância pode-se lançar mão de uma atividade de prática de docência online onde é disponibilizado para o discente um AVA (sala de aula virtual) com alunos reais. Para trabalhar o atributo colaboração, pode-se utilizar um simples trabalho em grupo para construir um conjunto de slides ou vídeo sobre um determinado assunto.

\subsection{Construção da ficha registro de acompanhamento do discente - FRAD}

A FRAD é um documento onde se insere todas as observações inerentes a cada discente durante as atividades. Pode ser elaborada tanto em papel ou em uma interface wiki do AVA.

É importante que o professor tenha em mente que o preenchimento da FRAD deve ser realizada assim que um determinado comportamento se enquadre em uma das pautas comportamentais, evitando com isso a perda do dado colhido. Desta forma, recomenda-se que o professor, ao entrar no AVA, tenha em mãos a FRAD, os objetivos afetivos e as pautas.

\subsection{Comunicação aos discentes}

Os professores do curso, antes do inicio de cada módulo ou disciplina, devem comunicar aos discentes o atributo a ser trabalhado e avaliado e o objetivo afetivo a ser alcançado.

\subsection{Realização da avaliação - o feedback}

$\mathrm{Na}$ avaliação do domínio afetivo é recomendável o uso de um feedback individualizado, uma vez que este tipo de avaliação não tem como objetivo a mensuração do atributo e sim uma análise do comportamento de cada discente nas atividades propostas.

O feedback é o momento em que professor e discente se reúnem para dialogar sobre os resultados da avaliação do domínio afetivo baseado nas observações registradas na FRAD. Constitui-se numa verdadeira avaliação formativa, pois se sustenta na observação do comportamento do discente em relação as pautas comportamentais traçadas no planejamento do curso.

O feedback ocorre em dois momentos: na metade de um módulo ou disciplina serve para indicar ao aluno os pontos fortes e as oportunidades de melhoria em relação ao comportamento que está sendo avaliado - e ao final do módulo ou disciplina para indicar o alcance ou não dos objetivos afetivos propostos no início do curso. 
Ao final da disciplina ou módulo, o professor deve realizar o feedback de fechamento e comunicar ao discente como foi seu desempenho para os atributos verificados.

\section{A aplicação da metodologia - $O$ curso ESIO}

O Estágio Setorial de Instrutores Online (ESIO) foi concebido para formar instrutores online capazes de ministrar os treinamentos e formações dos militares do Exército Brasileiro.

O curso foi realizado na modalidade a distância, contando com três docentes e 31 alunos oriundos de diversas unidades educacionais do Exército.

\subsection{Perfil profissiográfico}

A coordenação e os professores mapearam as capacidades que deveriam ser obtidas pelos discentes ao final do curso, dentre elas:

- organizar e planejar as aulas;

- promover atividades em grupo e individuais;

- estabelecer um processo de cocriação de conhecimentos;

- participar dos debates e atividades, interagindo com os alunos;

- desenhar a sala de aula virtual e utilizar as ferramentas fornecidas no AVA;

\subsection{Objetivos afetivos}

Para o ESIO, os objetivos afetivos foram selecionados pela coordenação e pelos professores envolvidos no curso. Tomou-se como base as características e atitudes comportamentais desejadas para um instrutor online no desempenho da função (BRASIL, 2000).

Assim, os objetivos definidos foram:

a) SOCIABILIDADE, capacidade de estabelecer interação com as pessoas propiciando um ambiente cordial;

b) TOLERÂNCIA, capacidade de respeitar e conviver com idéias, atitudes e comportamentos diferentes dos seus;

c) ORGANIZAÇÃO, capacidade de desenvolver atividades de forma sistemática e eficiente.

4.3 Pautas comportamentais

As pautas comportamentais do atributo afetivo sociabilidade foram:

a) Durante todas as atividades do fórum de discussão o discente interagiu com seus professores e companheiros de estágio, tratando-os com cordialidade e atenção. 
b) Durante as atividades do fórum de discussão o discente interagiu com seus professores, mas pouco com seus companheiros de estágio e tratou a todos com cordialidade e atenção.

c) Durante as atividades do fórum de discussão o discente interagiu com os companheiros de estágio, mas pouco com seus professores e tratou a todos com cordialidade e atenção.

d) Durante as atividades do fórum de discussão o discente não interagiu com os professores nem com seus companheiros de estágio.

e) Durante as atividades do fórum de discussão o discente interagiu com os professores e companheiros de estágio, porém não os tratou com respeito e atenção.

As pautas comportamentais do atributo afetivo tolerância foram:

a) Aceita, naturalmente, idéias, atitudes e comportamentos diferentes dos seus, sem estabelecer uma relação de animosidade com seus professores e companheiros de estágio.

b) Aceita, contra-argumentando, idéias, atitudes e comportamentos diferentes dos seus, sem estabelecer uma relação de animosidade com seus professores e companheiros de estágio.

c) Não aceita idéias, atitudes e comportamentos diferentes dos seus.

\subsection{Atividades pedagógicas}

Usar as ferramentas do AVA na sua forma básica dificulta implementar a avaliação da área a afetiva. Em razão disto, as atividades didáticas disponibilizadas no AVA foram cuidadosamente planejadas de forma a facilitar a observação dos atributos afetivos a serem avaliados no curso. Isso pode ser comprovado por intermédio da análise quantitativa de participações nos diversos fóruns disponibilizados aos alunos. No fórum simples, a média de interação não chega a 1 (uma) mensagem por aluno, pois existem àqueles que não participam. No fórum de réplicas e tréplicas a média de mensagens sobe para 3,4 (três vírgula quatro) e no fórum de integração de grupos o número de mensagens chega a 7 (sete) por aluno.

Para avaliar o atributo sociabilidade optou-se pelo fórum de integração de grupos. Esse tipo de fórum permite a elaboração de trabalhos a partir da colaboração dos componentes do grupo. É definido 1 (um) fórum para cada grupo. Este espaço se presta para discussões de assuntos, inclusão das versões de tarefas e acompanhamento da evolução dos discentes.

Os atributos organização e tolerância foram explorados na realização da atividade prática de docência online, onde os discentes produziram um curso online e interagiram com os alunos inscritos neste curso.

\subsubsection{Fórum de réplicas e tréplicas}


Baseado na prática proposta por Gilly Salmon (2004), foi aplicado a técnica de réplica e tréplica a partir de uma proposição elaborada por cada discente. O tema abordado foi escolhido pelo professor.

A justificativa para a utilização desta atividade: ela promove um alto grau de interação e intenso envolvimento dos participantes. Os discentes se posicionam, analisam os argumentos dos colegas e constroem contra-argumentações sólidas.

O tema utilizado versou, obrigatoriamente, sobre tópico de um dos módulos cursados e, neste caso, a escolha recaiu sobre: como atuar em um curso online utilizando estratégias não convencionais de aprendizagem e sobre o incentivo a construção da autonomia do aluno sem implicar no abandono por parte da tutoria.

Para dar início aos debates foram utilizados trechos do filme Karate Kid, disponíveis no youtube.

\subsubsection{Integração de Grupos}

Para desenvolver esta atividade de forma a observar os atributos afetivos foi necessário criar um fórum específico, organizado por grupos, e acompanhar diariamente a participação de cada discente neste fórum.

A tarefa em grupo solicitada foi elaborar um material interativo que tivesse possíveis respostas para as inquietações apresentadas na apostila do curso pela personagem "Prof. Pardoca!!!!!" (Figura 1).

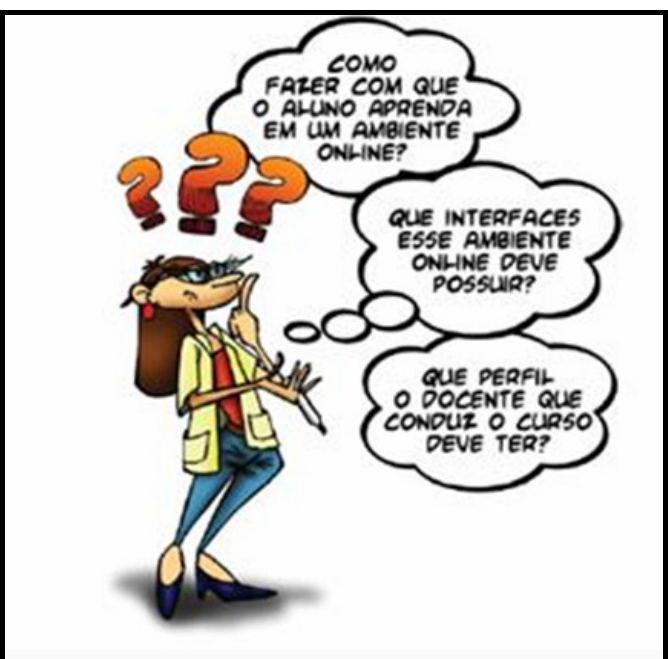

Figura 1 - Fórum de avaliação do atributo sociabilidade

Adicionalmente, foram fornecidas sugestões para nortearem os alunos no desenvolvimento do trabalho (Figura 2). 




Figura 2 - Sugestões para desenvolver a tarefa

Essa atividade permitiu que o professor estimulasse a colaboração. A sociedade requer sujeitos que saibam contribuir para o aprendizado do grupo do qual fazem parte, seja ensinando, respondendo ou perguntando (DALLACOSTA, 2010). Diferente de um fórum comum, no qual se teve 1 (uma) mensagem por aluno. No ESIO a participação dos alunos nesse tipo de fórum foi muito grande: em 1 (uma) semana a média de mensagens trocadas foi 7 (sete) por aluno.

\subsubsection{Prática de decência online}

Como o foco do curso foi a formação do professor online, foi elaborada uma atividade chamada de prática de docência online. Esta atividade durou 2 (duas) semanas e consistiu no planejamento, desenvolvimento e atuação em um mini curso online ministrado para até 8 (oito) alunos. A fim de verificar as melhores práticas docentes e possibilitar aos discentes do ESIO a exteriorização dos atributos afetivos, os alunos do mini curso possuíam comportamentos diversos como aqueles definidos por Okada e Almeida (2006): silêncio virtual, ausência, exaltação, não participação, controle, barreira tecnológica e espera atenta. Essa atividade causou um misto de apreensão e euforia. Ao final da atividade os discentes receberem os feedbacks afetivo e cognitivo e tomaram ciência do processo como um todo.

\section{$4.5 \mathrm{O}$ feedback}

Em função da necessidade de apresentar a avaliação de atributos afetivos para os dicentes, optou-se pelo uso da linguagem coloquial, dialógica, o que permitiu uma aproximação entre o discente o professor.

Em especial, para quebrar a barreira fria de um relatório escrito, optou-se por gravar podcasts individualizados para cada um dos discentes. Ao ouvir a voz dos professores, os discentes materializaram o indivíduo do outro lado da rede e tiveram uma maior receptividade para com as recomendações e avaliações.

As colocações feitas via podcasts foram sempre dentro de um processo envolvente como é possível observar no podcast enviado a um aluno: "A sua resposta para o aluno no dia x poderia ter sido um pouco mais dialógica, mais simpática. $O$ tom que você usou na mensagem pareceu meio agressivo. Tente usar uns emotions quando 
for ser um pouco duro com o aluno para dar uma amenizada. Estamos a distância, não sabemos como o aluno vai receber a mensagem do outro lado, então temos que "pegar leve". Cuidado com isso!!!! O tutor tem que cativar o aluno. Se ele for ríspido, ele perde a ligação afetiva com o aluno e o ensino/aprendizagem não acontece.(...). Nós sabemos que alguns alunos não tem o costume de ler o que o professor disponibiliza no ambiente, mas também o tutor não pode ser seco, responder simplesmente, "Leia a apostila!".”.

O uso do podcast no feedback também atua como um (re) acolhimento ao aluno, pois ao realizar a avaliação e recomendações também se esclarece pontos duvidosos e os desvios eventuais de uma tarefa são corrigidos. Isso pôde ser percebido na declaração de diversos alunos como, por exemplo, o manifestado após a prática docente: “...houve momentos em que fiquei triste 6 , mas depois de ouvir o podcast, eu estou mostrando a língua 9 Na ocasião eu fiquei muuuito bravo :-[I] e cheguei a chorar (:-...Mas agora, estou 9

\section{Considerações Finais}

No contexto descrito, a avaliação da aprendizagem pode extrapolar a simples verificação de conteúdos assimilados, a partir de uma avaliação que oportunize a averiguação de atitudes e comportamentos exteriorizados pelos discentes.

Se o comportamento for entendido como um conjunto de reações e atitudes, pode-se inferir que não importa o ambiente físico, presencial ou virtual, que as sensações experimentas pelos discentes serão as mesmas (OKADA e DE ALMEIDA, 2006).

Uma vantagem da aplicação dessa metodologia é que o aluno terá dois feedbacks: 1 (um) da área cognitiva e 1 (um) da área afetiva. Se ele não estiver alcançando o objetivo da área afetiva o professor, no meio do curso, dará dicas de como ele pode fazer para alcançar o objetivo afetivo, enfatizando os acertos e fazendo com que o aluno aprenda com o erro. O feedback mostrará para esse aluno o que ele deve fazer para aflorar essas competências que serão importantes para o desempenho da função.

Nesse primeiro trabalho foram avaliados apenas 3 (três) atributos. $\mathrm{O}$ desafio a seguir é identificar outros atributos que possam ser adequados as atividades pedagógicas do AVA e, consequentemente, avaliados em cursos online.

Como trabalhos futuros pretende-se incluir atributos da área afetiva atinentes a EAD em documentação do ensino militar e a reformulação da Norma de Elaboração do Conceito Escolar (NECE), haja vista que esta foi concebida para o ensino presencial (BRASIL,2000).

\section{Referências}

BLOOM, Benjamin. Taxionomia dos Objetivos Educacionais. Porto Alegre - Rio de Janeiro: Globo, 1983. 
BRASIL. Ministério da Defesa. Exército Brasileiro. Departamento de Ensino e Pesquisa - DECEx. Normas para Elaboração do Conceito Escolar. Portaria Nr 102/DEP, de 28 de Dezembro de 2000.

BRASIL. Ministério do Exército. Departamento de Ensino e Pesquisa - DEP. Definição de atributos da área afetiva. Portaria Nr 12/DEP, de 12 de maio de 1998.

BRASIL. Ministério da Defesa. Exército Brasileiro. Instrução Provisória da Avaliação do Comportamento. Centro de Estudos de Pessoal (CEP). Rio de Janeiro, 1998.

DALLACOSTA, Adriana. Formação para Docência Online com Uso Interativo do Ambiente Virtual de Aprendizagem. In: Anais do $16^{\circ}$ Congresso Internacional ABED de Educação a Distância. 2010. Disponível em: <www.abed.org.br/congresso2010/cd/252010185426.pdf>. Acesso em: 9/10/2010.

FERNANDES, Synésio Scofano. O ensino militar nas décadas de 70 a 90 . Revista da Cultura. Rio de Janeiro, ano VII, n.13, p. 14-19, 2008

LONGHI, Magali Terezinha; BEHAR, Patrícia Alejandra; BERCHT, Magda. A busca pela dimensão afetiva em ambientes virtuais de aprendizagem. In: BEHAR (org), Modelos Pedagógicos em Educação a Distância. Porto Alegre: Artmed, 2009

NUNES, Lina Cardoso; VILARINHO, Lúcia Regina Goulart. Avaliação da aprendizagem no ensino online em busca de novas práticas. In: SILVA e SANTOS (orgs), Avaliação da Aprendizagem em Educação online. São Paulo: Loyola, 2006.

OKADA, Alexandra Lilaváti P.; DE ALMEIDA, Fernando José. Avaliar é bom, avaliar faz bem. In: SILVA e SANTOS (orgs), Avaliação da Aprendizagem em Educação online. São Paulo: Loyola, 2006.

PESCE, Lucila; BRAKLING, Kátia. A avaliação do aprendizado em ambientes digitais de formação de educadores. Um olhar inicial. In: SILVA e SANTOS (orgs), Avaliação da Aprendizagem em Educação online. São Paulo: Loyola, 2006.

SOARES, Ivan. Avaliação do domínio afetivo em cursos online. In: Anais do $16^{\circ}$ Congresso Internacional ABED de Educação a Distância. 2010. Disponível em: $<$ http://www.abed.org.br/congresso2010/cd/252010122446.pdf>. Acesso em: 9/10/2010. 